\title{
Angiogenesis in cervical cancer is mediated by HeLa metabolites through endothelial cell tissue kallikrein
}

\author{
STRINIVASEN NAIDOO ${ }^{1}$ and DESHANDRA MUNSAMY RAIDOO ${ }^{2}$ \\ ${ }^{1}$ Department of Therapeutics and Medicines Management, Nelson R. Mandela School of Medicine, \\ University of KwaZulu-Natal, 4000 Durban, South Africa; ${ }^{2}$ Department of Psychiatry, \\ University of South Dakota, Sioux Falls, SD 57108, USA
}

Received April 21, 2009; Accepted May 25, 2009

DOI: $10.3892 /$ or_00000436

\begin{abstract}
High vascularity correlates with poor clinical outcome in cancer of the uterine cervix. We investigated whether human cervical cancer cell (HeLa) metabolites influenced endothelial cell proliferation through the serine protease, tissue kallikrein. The angiogenic potential of tissue kallikrein is proposed due to its proteolytic, mitogenic and invasive properties. Under pre-defined conditions, we examined the regulation of tissue kallikrein simultaneously in both endothelial and HeLa cells using immunochemistry, ELISA, cell proliferation assays and in situ RT-PCR. In an endothelial-cervical carcinoma conditioned-medium model, HeLa metabolites caused a dramatic decrease in endothelial cellular tissue kallikrein and a concomitant proliferation of endothelial cells. ELISA on the conditioned media showed a dose-dependent increase of tissue kallikrein, while in situ RT-PCR demonstrated no change in tissue kallikrein mRNA in both endothelial and HeLa cells when challenged with each other's metabolites. This demonstration of the ability of cervical cancer to simultaneously manipulate both tissue kallikrein processing within endothelial cells and angiogenesis is novel. Should this occur in vivo, the tissue kallikrein released from the endothelial cells into the microenvironment may simultaneously degrade the matrix and elicit a mitogenic effect by promoting angiogenesis. Pre-treatment with TK inhibitors and/or anti-angiogenic therapies may prove to benefit future cervical cancer patients.
\end{abstract}

\section{Introduction}

Cancer of the uterine cervix is the second most common malignancy in women and remains a leading cause of cancerrelated deaths for women in developing countries (1). Poor clinical outcome has been found to correlate with increased

Correspondence to: Dr Strinivasen Naidoo, Department of Therapeutics and Medicines Management, Nelson R. Mandela School of Medicine, University of KwaZulu-Natal, Private Bag X7, Congella 4013, Durban, South Africa

E-mail: naidoot@ukzn.ac.za

Key words: cervical cancer, HeLa, tissue kallikrein, angiogenesis tumour size, stage and vascularity (2-4). The importance of the latter is linked to the therapeutic potential of radiotherapy in cervical cancer (5) and is supported by a consensus statement which proposed the intra-tumour microvessel density ('hot spot') technique as the method of choice for measuring angiogenesis (6).

Angiogenesis is the recruitment of new blood vessels from the pre-existing microvasculature that occurs in normal tissue and tumours (7-11). Thus, many primary tumours are able to establish continuity with the circulation to obtain nutrients and also to systemically shed metastatic cells which then target secondary sites in distant organs (12). Tumour angiogenesis is a tightly-regulated cascade mediated by angiogenic cues emanating from stromal elements in the host organ environment (13). Some pro-angiogenic factors shown to be involved in cervical cancer include vascular endothelial growth factor (VEGF) (14-16) and platelet-derived growth factor (PDGF) (17). However, there are no studies on the role of tissue kallikrein (TK) in cervical cancer angiogenesis even though TK and its gene, KLK1 (EC 3.4.21.35) have been shown to induce angiogenesis in an ischaemic hind-limb model (18) and to be present in the endothelial cells of human umbilical cord vein (HUVEC) (19) and human coronary artery (20).

TK is a serine protease whose primary function is to cleave kininogen in order to release bradykinin (BK). Other functions of TK include the proteolytic breakdown of progelatinase and pro-collagenase (21) with concomitant destabilisation of the stroma, thereby promoting the migration of both endothelial and tumour cells (22). Although TK and KLK1 have been demonstrated in endothelial cells $(19,20)$ and in tumours of the human stomach (23), oesophagus (24) and breast (25), there are no studies on the role of the kallikrein-kinin system (KKS) in the pathogenesis of cervical cancer. Components of the KKS are also considered to form the first line onset of inflammation (26), a process described as important in the pathogenesis of cervical cancer $(27,28)$, and the vascularity observed in cervical cancer (29). The involvement of TK in most biological processes considered to be crucial in cervical cancer, namely, tumourigenesis, angiogenesis and inflammation, makes TK an ideal candidate for further study into the pathogenesis of cervical cancer.

Previous angiogenesis models have studied neo-vascularisation without simultaneously examining any concomitant 
effects of tumour cells on structural angiogenesis and angiogenic mediators. Thus, in order to study the influence of cervical cancer on both structural angiogenesis and the angiogenic mediator, TK, HUVECs were exposed to metabolites from HeLa, a highly metastatic cancer of the human uterine cervix (30). This HUVEC/HeLa challenge model was optimised so that: i) TK gene expression, determined by in situ RT-PCR, ii) TK sequestration, determined by immunochemistry and ELISA, and iii) structural angiogenesis, determined by MTT cell proliferation assay, could be examined simultaneously.

\section{Materials and methods}

Cell culture. HUVECs were obtained as primary cultures and proliferated according to supplier's instructions (BioWhittaker Inc., Walkersville, MD, USA) using a growth medium kit $\left(\right.$ EBM $^{\circledR}-2$ Bullet kit). The immortal HeLa line was obtained from Highveld Biological, National Repository for Biological Material of the Cancer Association of South Africa, Sandringham, South Africa, and grown in DMEM supplemented with $10 \%$ FBS.

$2 D$ challenge model. This model was optimised previously (19). Briefly, HUVECs $\left(5 \times 10^{3}\right.$ cells $\left./ \mathrm{cm}^{2}\right)$ and HeLa cells $\left(2 \times 10^{3}\right.$ cells $\left./ \mathrm{cm}^{2}\right)$ were plated onto 8 -well chamber slides (Iwaki, Tokyo, Japan). At approximately 60\% confluency, conditioned medium was extracted from each line and used to dose the other cell line at concentrations of 10,25 and $50 \%$, now designated 'challenge medium'. Thus, metabolites were presented to proliferating cell lines in a dose-controlled manner. After $24 \mathrm{~h}$, the spent challenge medium was removed for TK measurement by ELISA while the cells on the chamber slides were serum-cleared and fixed in acetone/methanol $(1: 9, \mathrm{v} / \mathrm{v})$. Chamber slides were stored at $4^{\circ} \mathrm{C}$, under RNasefree conditions, until TK immunochemistry and TK mRNA assays could be performed.

TK immunochemistry. The TK primary antibody, an antihuman polyclonal goat IgG raised against a recombinant human TK, was isolated and fully characterised for specificity and sensitivity, as described previously (31). The conventional linked streptavidin-biotin (LSAB) immunolabelling method for challenged cells was performed as described previously (19). The antibody method control was normal human submandibular gland, a known source of TK (32), and was used to demonstrate TK as described previously (33). To distinguish between the two cell types, von Willebrand's Factor (vWF; Sigma, St. Louis, MO, USA) and cytokeratin (CK-19; Dako, Cambridgeshire, UK) was used to immunostain endothelial cells and HeLa cells, respectively. Approval for the collection and histological processing of normal submandibular gland tissues from post-mortem had been granted previously by the University of KwaZulu-Natal Biomedical Ethics Committee.

Immunostained slides were viewed, using a bright field/ phase contrast microscope (DMLB; Leica, Heidelberg, Germany) coupled to a digital camera (DFC 300FX, Leica). The C-mount adaptor between microscope and camera had a x10 magnification. Fluotar objective lenses (Leica) were used (x20, x40 and x100 magnification with numerical apertures of $0.50,0.70$ and 1.3, respectively). Twenty-four-bit tagged image format (TIFF) images were captured using Leica IM50 ${ }^{\circledR}$ image capture software. Regions of interest were selected from converted 8-bit black and white images. The grey scale intensity of specific label was quantified using AnalySIS ${ }^{\circledR}$ Five (Soft Imaging Systems, Münster, Germany) image analysis software with pre-determined threshold range-limited $\operatorname{pixel} / \mu \mathrm{m}^{2}$ values.

TK ELISA. To quantify TK in extracts of spent challenge media from both HUVECs and HeLa, a sandwich ELISA was used, as described previously (34). The following were controls: i) serial human urinary kallikrein standards (40 ng/ml to $0.625 \mathrm{ng} / \mathrm{ml}$; Calbiochem, San Diego, CA, USA), ii) PBS blanks, and iii) serial internal-standard controls (control urine, 1:8-1:512). The University of KwaZulu-Natal Biomedical Ethics Committee had previously granted permission for control urine to be collected from healthy volunteers.

Cell proliferation assays in the challenge model. HUVECs and HeLa, plated into a 96-well cell culture microtitre plate (Corning Costar, NY, USA) at densities of $1.5 \times 10^{4}$ and $8 \times 10^{3}$ cells/well, respectively, were grown to $60 \%$ semiconfluency. Following the challenge model where both endothelial cells and HeLa cells were each fed 10, 25 and 50\% concentrations of challenge medium from the other cell line for $24 \mathrm{~h}$, proliferation of both cell types were measured as follows: $10 \mu \mathrm{l}$ of $5 \mathrm{mg} / \mathrm{ml}$ MTT [3-(4,5-dimethylthiazol-2yl)-2,5-diphenyl tetrazolium bromide salt; Sigma] was mixed with $100 \mu 1$ of pre-warmed $\left(37^{\circ} \mathrm{C}\right)$ cell-specific medium and then added to the cells at $37^{\circ} \mathrm{C} / 5 \% \mathrm{CO}_{2}$ for $4 \mathrm{~h}$. The MTT solution was replaced with $100 \mu 1$ dimethylsulfoxide (DMSO, Sigma) and the plate incubated for a further $1 \mathrm{~h}$ at $37^{\circ} \mathrm{C} / 5 \%$ $\mathrm{CO}_{2}$. Thereafter, the absorbance at $595 \mathrm{~nm}\left(\mathrm{~A}_{595 \mathrm{~nm}}\right)$ of each well was read at on a microplate reader (Model 3550; Bio-Rad, CA, USA), and this value was normalised using the $\mathrm{A}_{595 \mathrm{~nm}}$ of non-challenged cells as a baseline $100 \%$ cell proliferation.

In situ RT-PCR (IS RT-PCR) for TK $m R N A$. The method used was described previously (19). Challenged HUVEC and HeLa cells were tested for TK mRNA with the following synthetic oligonucleotide primers: KLK1-160F, 5'-CTGTACCATTTC AGCACTTTC; KLK1-742R, 5'-GCCACAAGGGACGTAGC; KLK1-790R, 5'-TCACATAAGACAGCACTCTGA (MWGBiotech AG, Ebersberg, Germany). Following thermal cycling, optimised previously (19), DIG-labelled mRNA were immuno-detected with nitro-blue tetrazolium/bromochloro-indoyl phosphate. Immunostained slides were viewed and images captured using the Leica microscope-camera system described above.

\section{Results}

Phenotypic growth profiles in the challenge model. Growth profiles of the challenged HUVECs were described previously (19). Briefly, HUVECs established an approximately $60 \%$ monolayer confluency 4 days post-seeding on 2D growth surfaces. Uniform plating distribution ensured sufficient growth and cell spreading to facilitate challenging these cells with HeLa conditioned-medium. Upon challenge with HeLa metabolites, HUVECs, in general, demonstrated no marked 


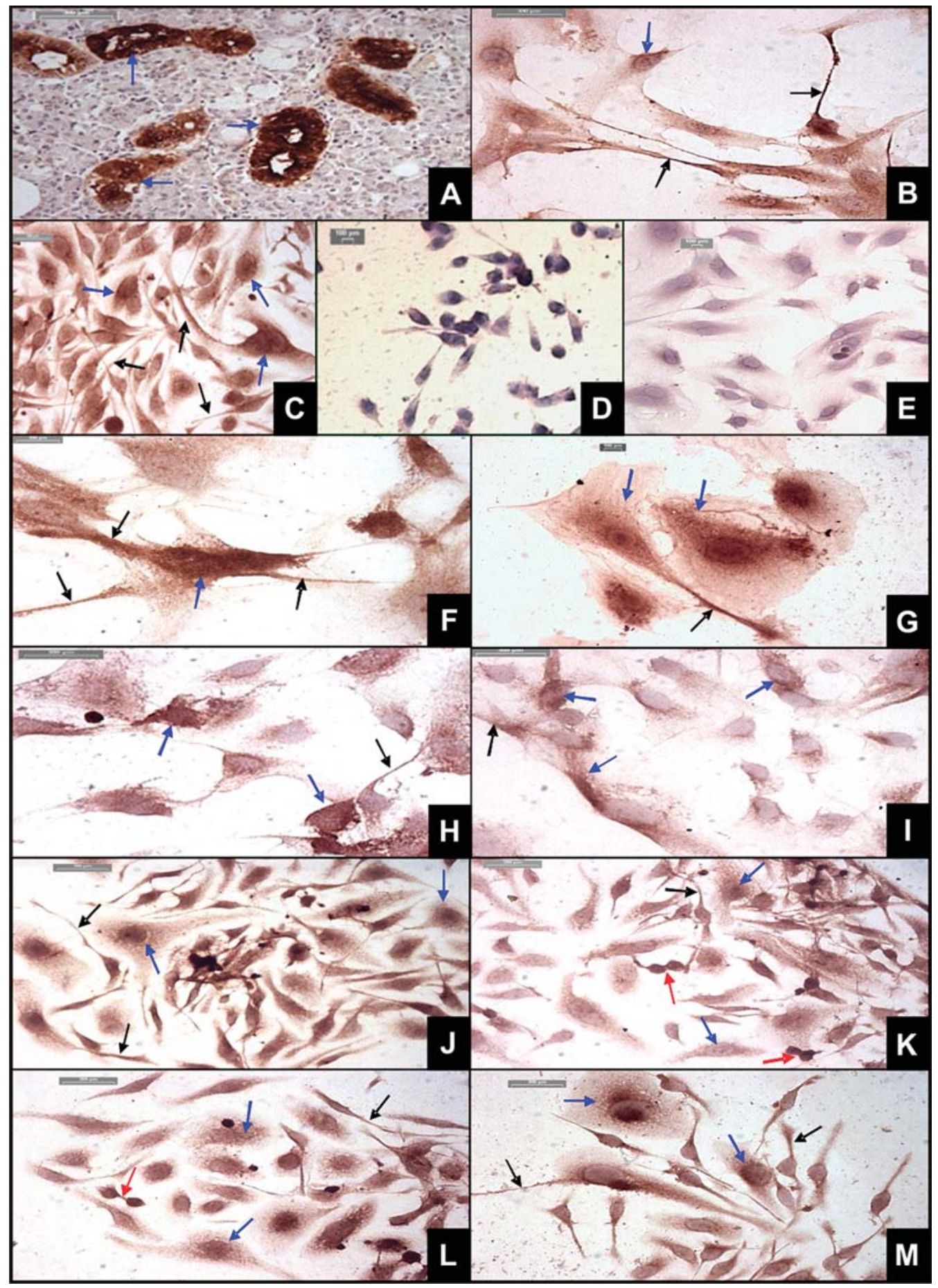

Figure 1. TK immunodetection in the HUVEC/HeLa challenge model: normal human salivary gland (SG) served as a method control (A) where TK label is depicted as a brown precipitate (diaminobenzidine, DAB) in salivary gland duct cells (blue arrows) but not within acinar cells (x200). The HUVEC phenotype (B) was validated by von Willebrand Factor staining in peri-nuclear (blue arrow) and interend othelial projections (black arrows) of unchallenged HUVECs (x400). Unchallenged HeLa cells (C) demonstrated peri-nuclear (blue arrows) and cell-extension (black arrows) cytokeratin (CK-19; x400). HeLa (D, x200) and HUVEC (E, x400) were negative method controls. Unchallenged HUVECs (F, x400), 10\% challenged HUVECs (G, x400), 25\% challenged (H, x1000) and 50\% challenged (I, x400) showed TK cytoplasmic (blue arrow) and cell extension (black arrows) staining. Unchallenged HeLa (J, x400), 10\% challenged (K, x400), $25 \%$ challenged (L, x400) and 50\% challenged (M, x400) demonstrated diffuse cytoplasmic (blue arrows) and cell-cell extension (black arrows), with some mitotic figures (red arrows) evident in $(\mathrm{K})$ and $(\mathrm{L})$. Note that scale bars on $(\mathrm{A})-(\mathrm{C})$ and $(\mathrm{H})-(\mathrm{M})=300 \mu \mathrm{m}$ whilst the rest $=100 \mu \mathrm{m}$.

phenotypic change although there were some examples of spontaneous cord-like structure (CLS) formation. In contrast, HeLa cultures exhibited typical pleiomorphic, monolayer topology in the log-phase of growth, and subsequent cell clusters exhibited peripheral expansion and bridging between smaller cell conglomerates. Upon challenge with HUVEC metabolites, HeLa cell morphology did not appear to change.
Careful preparation of cell cultures minimised cell stress and consequent necrosis.

Immunostaining controls. In the submandibular gland control tissue, positive TK immunostaining was demonstrated within the ductal epithelial cells $(31,32,35)$, but was absent within the acinus (Fig. 1A). HUVEC and HeLa phenotypes were 
confirmed with the cell-specific markers vWF and CK-19, respectively, and the non-challenged HUVECs and HeLa served as cell culture controls. In the endothelial cells, vWF staining was observed in membrane extensions and peri-nuclear regions as well as in intercellular junctions in spontaneous CLS (Fig. 1B). In HeLa monolayers, CK-19 staining was observed in the peri-nuclear cytoplasm as well in membrane extensions (Fig. 1C). Omission of the primary antibody (TK, vWF or CK-19) and replacement with dilution buffer in the method controls demonstrated no non-specific label in both HeLa and HUVEC monolayers (Fig. 1D and E, respectively). In order to validate endothelial cell function in the challenge model, 50\% challenged HUVECs retained vWF expression (data not shown).

TK in non-challenged HUVECs. Immunolabelling was observed in non-challenged control HUVECs $(n=6$; Fig. 1F) in $50-70 \%$ of cells in each field of view. In areas of confluency, there was low intensity, evenly-distributed cellular staining. In other regions, HUVECs demonstrated strong cytoplasmic and cell membrane labelling accompanied by intense staining in cell-cell extensions and contacts. Further, non-challenged HUVECs, embedded within confluent colonies, appeared to have little or no stain at all. Since microscopic assessment is always subject to observer bias, cellular immunostaining intensity in the HUVEC/HeLa challenge models was further quantified by image analysis (discussed later).

TK in challenged HUVECs. As the concentration of tumour challenge medium $[\mathrm{Tu}]$ increased, the amount of TK immunolabel in HUVECs appeared to visually decrease (Fig. 1G-I). Indeed, the TK label became more defined even though there appeared to be a reduction in the distribution and the intensity of staining (data not shown). Further, challenged HUVECs demonstrated some CLS formation and staining in larger cells appeared to localise on the opposite side of the cytoplasm to that of actual contact with neighbours. The visual staining intensities of cell contacts and cell extensions appeared to be similar (intense) in all challenged sets of HUVECs.

TK in non-challenged and challenged HeLa. Immunolabelling patterns for TK on HeLa cells in the challenge model $(n=6)$ are demonstrated in Fig. 1J-M. In every field of view examined, approximately $70-90 \%$ of challenged HeLa cells immunostained for TK. Non-challenged HeLa demonstrated diffuse staining in confluent regions especially on cells in the midst of colonies (Fig. 1J). There was extensive staining in semiconfluent regions with individual cells exhibiting intense label on mitotic figures and cell-cell contacts. As endothelial challenge medium [En] increased, the challenged HeLa cells demonstrated little/no label in confluent regions, extensive and moderate label in semi-confluent regions with intense, whole-cell TK label on most of the other cells including mitotic figures (Fig. 1K-M). Many of the 50\%-challenged HeLa cells demonstrated thin and long cellular extensions that overlapped each other and labelled intensely for TK.

Image analysis. Six independent challenge experiments $(\mathrm{n}=6)$ were performed and 30-60 cells were analysed for each group. TK immunolabelling intensities were translated into box-plot histograms. Kruskal-Wallis and Dunn's Multiple Comparison
Post Hoc Test was used to determine overall significance and intergroup significance, respectively $(\mathrm{P} \leq 0.05)$. A significant difference $(\mathrm{P}<0.0001)$ in TK labelling intensities was demonstrated between non-challenged HUVECs $\left(2.41\right.$ pixels $\left./ \mu \mathrm{m}^{2}\right)$ and each of the challenged HUVEC groups (2.13, 2.33 and 4.55 pixels $/ \mu \mathrm{m}^{2}$, respectively; Fig. 2Ai). Small confidence interval ranges boosted the robustness of significance. In summary, the overall trend appeared to be a significant decrease in the intensity of TK labelling on HUVECs as [Tu] increased.

Similar analysis of [En]-challenged HeLa cells demonstrated no significant differences in TK intensity amongst any of the four groups (Fig. 2Aii) with mean TK intensity values for non-challenged and challenged HeLa cells measuring $5.86,5.51,4.77$ and 5.29 pixels $/ \mu \mathrm{m}^{2}$, respectively. Thus, HUVEC metabolites did not appear to elicit any change in TK immunoreactivity in HeLa cells.

ELISA. To control for inter- and intra-assay variations as well as validate ELISA results of the samples, pooled urine standards were used. Further, in order to exclude the growth: time ratio as a possible factor influencing the release of TK into the conditioned-medium, sample aliquots of conditionedmedium from HUVECs and HeLa, grown to almost complete confluency, revealed no significant increase in TK content from day 0 (day of plating) until confluency, indicating that time did not mitigate TK output (data not shown). Six independent TK ELISAs $(n=6)$ were performed on challenge medium, with each sample measured in triplicate. The TK content in each challenge group was translated into box-plot histograms. Kruskal-Wallis and Dunn's Multiple Comparison Post Hoc Test was used to determine overall significance and intergroup significance, respectively $(\mathrm{P} \leq 0.05)$. The medium of non-challenged HUVECs contained a mean TK concentration of $18.72 \mathrm{ng} / \mathrm{ml}$ (Fig. 2Bi). However, when these cells were challenged with [Tu], TK significantly increased to $21.65 \mathrm{ng} / \mathrm{ml}$ (25\%, P $\leq 0.04)$, and peaked at $20.81 \mathrm{ng} / \mathrm{ml}(50 \%, \mathrm{P} \leq 0.02)$, suggesting that HeLa metabolites increasingly induced HUVECs to release TK into their surrounding microenvironment in a dose-dependent manner. Fig. 2Bii demonstrates TK released into the growth medium by challenged HeLa cells, where no statistical differences could be demonstrated between the non-challenged and challenged groups. Thus, neither the presence nor the concentration of HUVEC metabolites appeared to have any effect on the amount of TK released from HeLa cells.

Cell proliferation. To control for the proliferative effects that HUVEC metabolites would have on the growth potential of HUVECs themselves, these cells were challenged with [En] and the cell proliferation measured (data not shown). In the HUVEC-HeLa challenge model, 6 independent MTT assays $(n=6)$ were performed where the quantitation of challenged HUVECs demonstrated a significant increase in cell proliferation (Fig. 2Ci). For each of the [Tu] concentrations used $(10,25$ and $50 \%)$, there was a statistically significant increase (192.55, 201.59 and $211.42 \%$, respectively) compared with the non-challenged HUVEC treatment group. A similar but non-significant trend was observed in HeLa cells, with an increase in cell number in each of the 10, 25 and $50 \%$ 


\section{A: Image analysis}

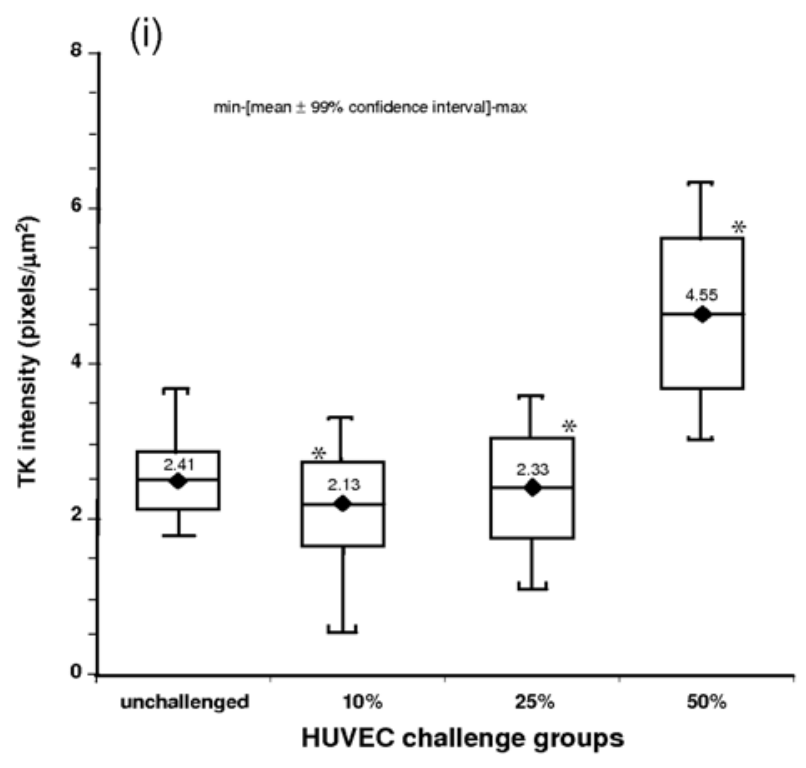

(ii)

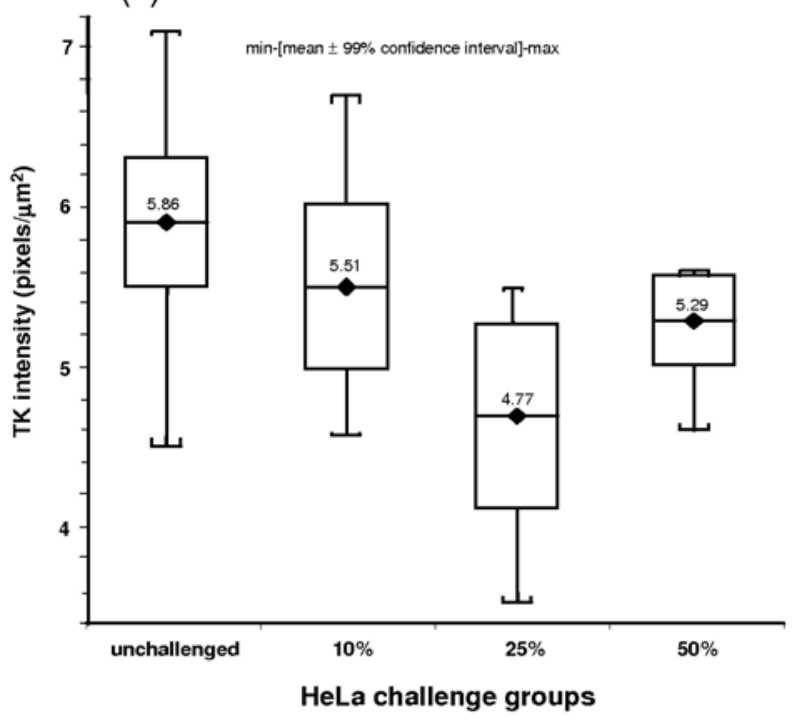

\section{B: TK ELISA}
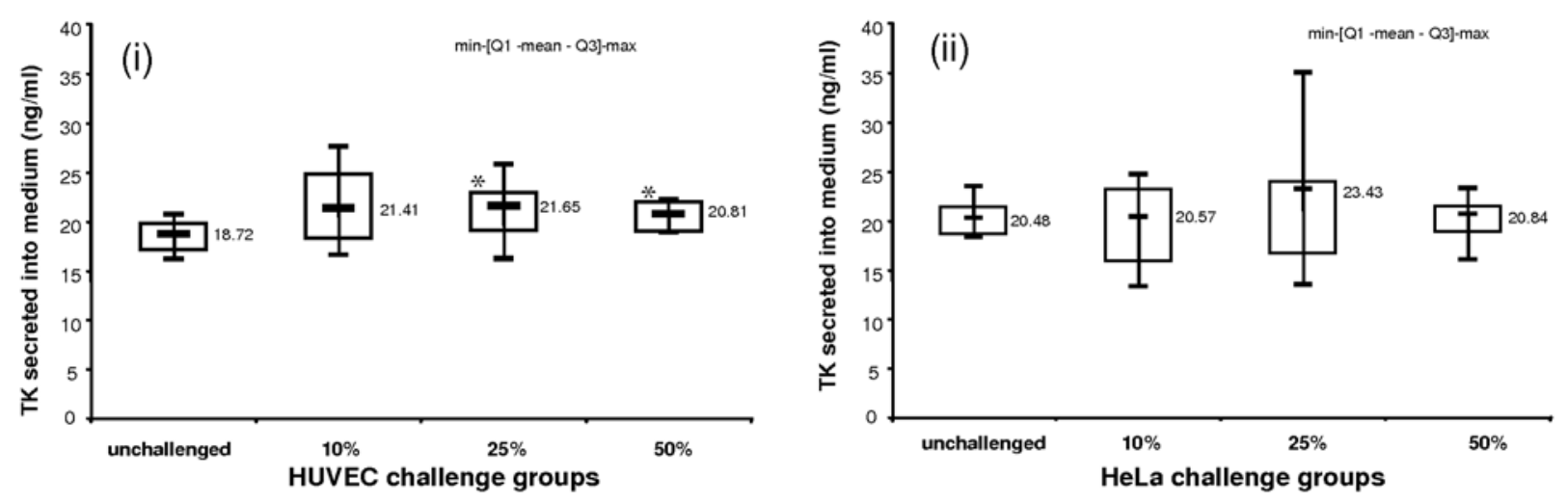

\section{C: Cell proliferation}
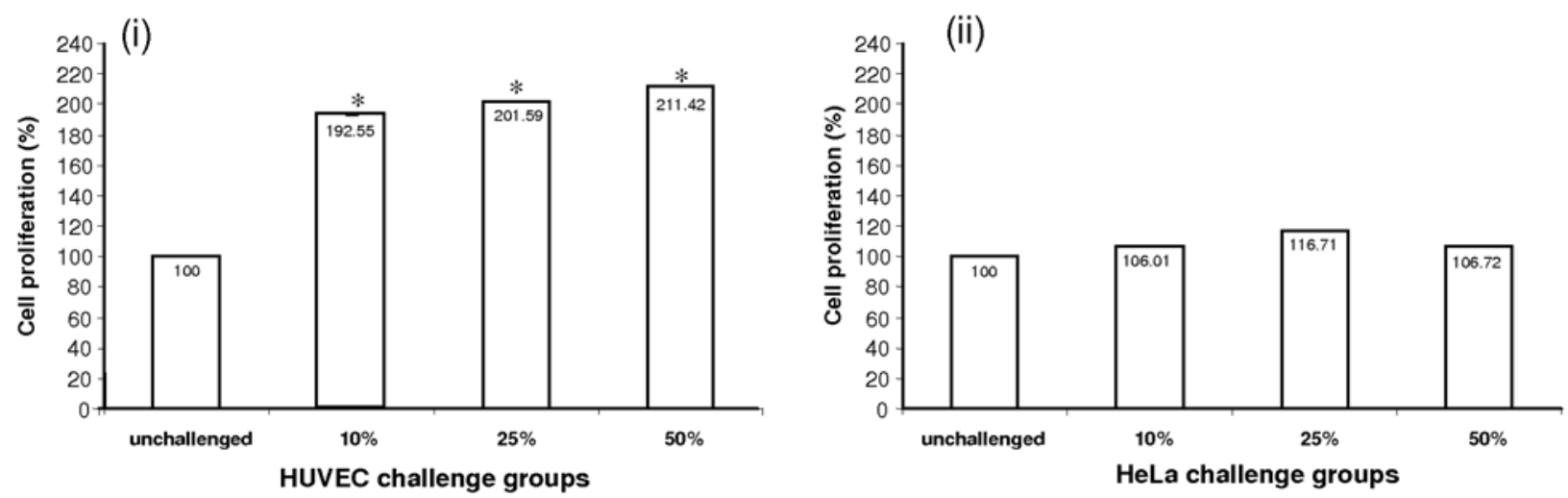

Figure 2. TK image analysis, TK secretion and cell proliferation in the HUVEC/HeLa challenge model. Quantification of TK staining intensity in HUVEC and HeLa treatment groups $(n=6)$, by image analysis $(A)$, demonstrated significance amongst the HUVEC groups only. Measurement of TK content in conditionedmedium of the HUVEC and HeLa treatment groups $(n=6)$, by ELISA (B), revealed significance only amongst the HUVEC treatment groups. Cell proliferation measurements of challenged HUVEC and HeLa ( $n=6)$, determined by MTT assay (C), showed significant increases in HUVEC cell proliferation only. Asterisk indicates statistical significance compared to the control $(\mathrm{P} \leq 0.05)$.

challenged groups (106.01, 116.71 and $106.72 \%$, respectively) compared with non-challenged HeLa cells (Fig. 2Cii). The Student's t-test (36) was used to assess the statistical significance $(\mathrm{P} \leq 0.05)$ between groups.
IS RT-PCR controls. The human submandibular gland positive method control demonstrated TK mRNA in the salivary gland duct cells (Fig. 3A). The non-challenged HUVEC and HeLa served as positive cell culture controls for IS RT-PCR 


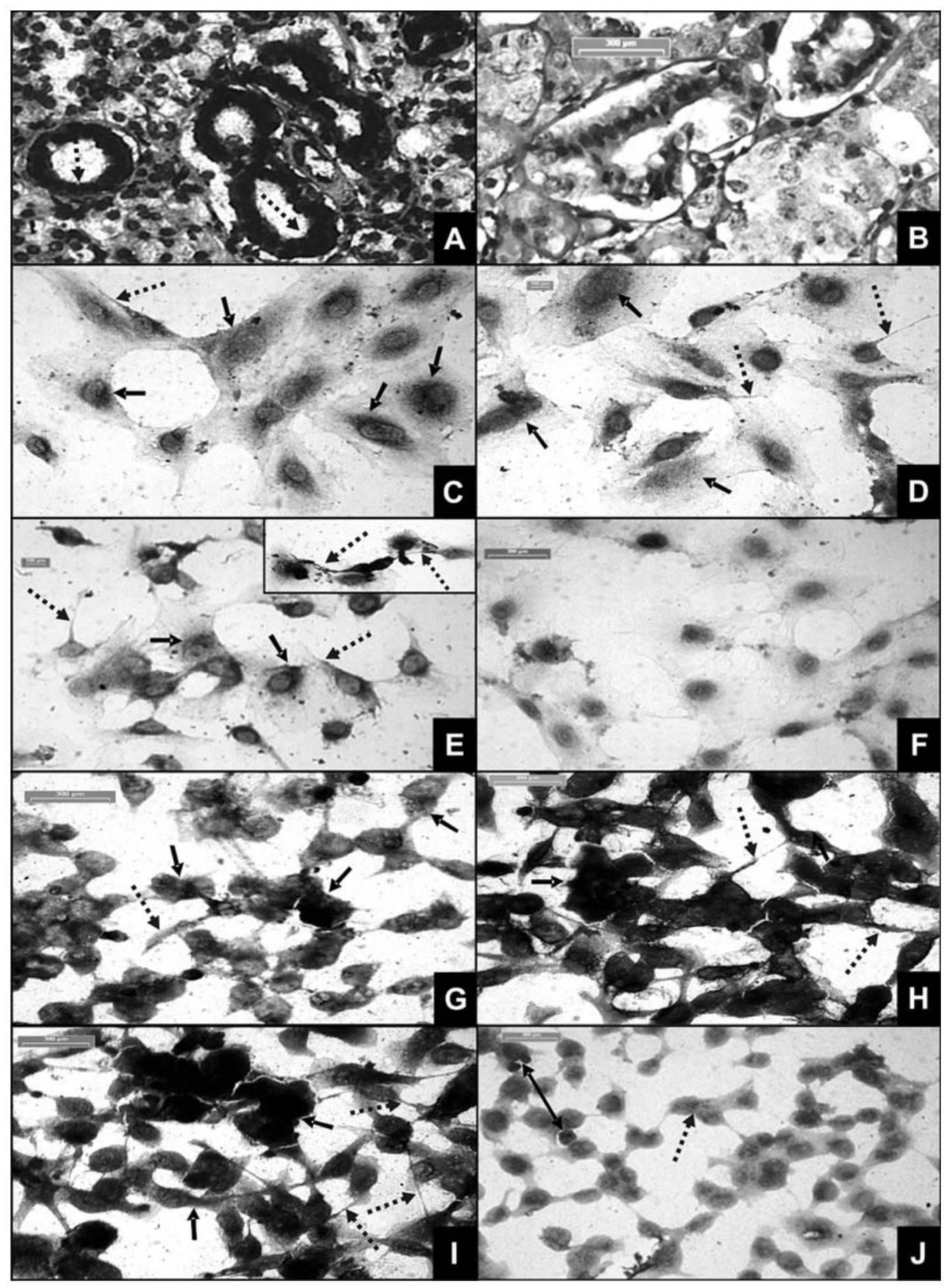

Figure 3. TK mRNA in the HUVEC/HeLa challenge model by in situ RT-PCR. TK mRNA label was visualised as an intense blue-black colour precipitated by the chromogen, nitro-blue tetrazolium/bromo-chloro-indoyl phosphate. Normal human salivary gland control tissue (A) demonstrated TK mRNA (broken arrows) in the cytoplasm of ductal cells but not in the acinar cells (x200) or in the salivary gland negative control (B, x200), Unchallenged (C, x400), 10\% challenged (D, $\mathrm{x} 400$ ) and 50\% challenged (E, x400) HUVECs demonstrate extensive peri-nuclear TK expression (black arrows). Cellular extensions also show TK mRNA (broken arrows) in (C), (D), (E) and (E) inset, while HUVEC method control (F) demonstrates no immunostaining (x400). Unchallenged (G, x400), 10\%challenged $(\mathrm{H}, \mathrm{x} 400)$ and 50\%-challenged ( $\mathrm{I}, \mathrm{x} 400) \mathrm{HeLa}$ cells displayed extensive cytoplasmic (black arrows) and cell extension (broken arrows), while HeLa negative control $(\mathrm{J}, \mathrm{x} 400)$ demonstrates no cellular mRNA but does indicate mitosis (broken arrow) as well as apoptosis (double-head arrow). Note, scale bars on (B) and (F)-(J) $=300 \mu \mathrm{m},(\mathrm{D})$ and $(\mathrm{E})=100 \mu \mathrm{m}$.

and both cell types demonstrated TK mRNA label within their cytoplasm (Fig. 3C and G). Omission of the primers during both the reverse transcriptase and PCR reactions confirmed the specificity of this labelling. The negative control on the salivary gland showed an absence of TK mRNA label in the cytoplasm of the duct cells but some non-specific nuclear labelling (Fig. 3B). This artefact, seen in both positive and negative tissue controls (as well as in all cultured cells), was due to non-specific nuclear labelling that occured during the PCR reaction where Taq DNA polymerase screens nuclear DNA for nicks caused by DNase, and then repairs these fragments. Consequently, DIG-dUTP from the nucleotide pool is incorporated into the repaired nuclear strands and this manifests as nuclear labelling. Negative method controls for 
HUVECs and HeLa also demonstrated no cytoplasmic mRNA labelling, although non-specific nuclear staining was evident (Fig. 3F and J, respectively).

TK mRNA in HUVECs. Both non-challenged and challenged HUVECs displayed TK mRNA in their cytoplasm as well as non-specific nuclear staining (Fig. 3C-E). Specific label was generally localised to peri-nuclear regions in confluent and semi-confluent cells. Those cells that remained isolated in culture and those that exhibited cell-cell contacts demonstrated distinct mRNA within cellular extensions (Fig. 3E, inset). In many instances, these extensions stained more intensely than those of their semi-confluent/confluent neighbours. No visual intensity differences could be discerned between challenged and non-challenged HUVECs, or amongst the various challenged HUVEC groups. These observations also included the few spontaneous CLS formations. An average of $60-80 \%$ of cells labelled for TK mRNA in all groups (mean in 5 fields of view, $n=6$ ).

TK mRNA in HeLa. Intense TK mRNA was visualised on both non-challenged (Fig. 3G) and challenged HeLa (10\% and 50\%: Fig. $3 \mathrm{H}$ and I, respectively) in most cells demonstrating complete cytoplasmic labelling for TK mRNA. This labelling was especially prominent in cells within confluent regions, cell extensions, cell-cell contacts and actively dividing cells. In areas of cell aggregation, complete cellular staining occurred. There were no visual differences in TK mRNA staining patterns between non-challenged and challenged HeLa, or amongst the various challenged HeLa groups.

\section{Discussion}

Although the in vivo milieu is the ideal environment for studying tumour-angiogenesis, in vitro systems are also useful since they relate well to combination models of cancer and endothelial cells. Conditioned-medium models, however, afford countless biochemical variations and, by limiting functional parameters, the influence(s) of biochemical elements can be defined. Thus, the present model i) allowed angiogenic tendencies of HUVECs to be investigated whilst under the tempero-spatial influence of metabolites from cervical cancer cells, and ii) afforded bi-directional analysis of the influence of tumour and endothelial factors on cell proliferation and TK processing.

The 15 tandemly-located human TK genes on the long arm of chromosome 19 are expressed in a wide array of tissues, mainly those that are under steroid hormone control (37). The localisation of both TK and TK mRNA in HeLa cells support the expression of TK in human cervical carcinoma. Although previous studies, including our own, have demonstrated TK expression in various human tumours and cultured human tumour cells $(19,23,24,38-41)$, this is the first study demonstrating TK in human cervical cancer HeLa cells. A previous study demonstrated the presence of human kallikrein 7 (hK7) in $80 \%$ of human cervical adenocarcinoma samples examined versus $46 \%$ of normal cervical tissue (37), suggesting that increased hK7 expression might play a role in the pathogenesis of cervical adenocarcinoma. A recent study indicated that relatively high levels of many human tissue kallikrein-related peptidases (KLK) are present in human cervico-vaginal fluid where they may activate anti-microbial proteins as they do in perspiration (42). An important extension of our study will be to examine the differential expression of TK in normal cervical tissue and various stages of cervical cancer since such a study will contribute to our understanding of the changing functional roles of TK during progression, invasion and metastasis in cervical cancer.

The involvement of the KKS in angiogenesis has been demonstrated by the expression of TK in bovine angiogenic endothelial cells $(19,20)$, non-angiogenic HUVECs and human coronary artery endothelial cells (20). In this study, we also demonstrate the presence of TK and TK mRNA in angiogenic HUVECs, but this is the first demonstration of the ability of metabolites from cervical cancer cells to induce the release of TK from HUVECs. In addition, we found that challenging endothelial cells with metabolites from human cervical cancer cells significantly increase the proliferation of HUVECs to form CLS while simultaneously reducing the amount of immunoreactive cellular TK, in a dose-dependent manner. The reduction in cellular TK was associated with a concomitant increase in TK within the media, supporting a proteolytic action of TK on the ECM. This novel finding that alludes to the dynamic manipulation that tumours may simultaneously exert over both TK expression and angiogenesis is supported by previous reports of TK being a stromal protease and mitogen (43). It is also possible that these cancer metabolites modify downstream protein sequestration signals. Another explanation, as suggested by our previous study (19), is that the apparent up-regulated TK metabolic activity is a function of its preactivation and half-life $\left(t_{1 / 2}\right)$. Cellular TK, stored as inactive prekallikrein, is usually activated to TK which has proteolytic functions both within the endothelial cell and in the extracellular environment, until it is sequestered by inhibitors such as kallikrein binding protein (KBP), Protein $\mathrm{C}$ and kallistatin, resulting in a $t_{1 / 2}$ of several hours (44-46). Our anti-TK IgG detected both the prekallikrein stored within unchallenged HUVECs as well as TK released from HUVECs following activation by cervical cancer cell metabolites. Although other studies, using PCR, amidolytic activity and receptor antagonists have demonstrated the release of active TK by human vascular endothelial cells (20), none have demonstrated a dosedependent release due to tumour metabolites. Here, we have been able to show, by ELISA, a significant increase in total kallikrein content in the spent medium of challenged HUVECs. This increase appeared to be in direct response to tumour metabolite concentration in the conditioned-medium, and suggests functional activation of pre-kallikrein. This latter effect is supported by the studies of Shih and co-workers who showed that ovarian cancers secrete kallikreins $6,7,8$ and 10 (47) and the Yayama group who have shown that activated TK is continually secreted by HUVECS (20). Further, in the present study, HeLa metabolites caused significant increases in HUVEC proliferation, by as much as $200 \%$. It is possible that HeLa, originating from a highly vascular and aggressive cervical tumour, requires a strong angiogenic profile that is achieved by the ability of HeLa metabolites to simultaneously influence pro-angiogenic factors such as VEGF and TK (and others), and endothelial cell proliferation. In our model, it is possible that TK, released in response to 
tumour metabolite signals, has proteolytic and pro-invasive functions that are required at the leading edges of neovasculature development. Other pro-angiogenic factors have also demonstrated variable functions, e.g. $\mathrm{VEGF}_{121}, \mathrm{VEGF}_{165}$ and $\mathrm{VEGF}_{189}$ display differing biological activities due to specific microenvironments at different anatomical sites (48).

Previous studies in animal models have reported that inflammatory stimuli promote the release of cell-bound TK with no decrease in TK mRNA levels (49). In humans with ulcerative colitis and Crohn's disease, Stadnicki and coworkers showed that TK secretion resulted in a significant decrease in TK levels within the inflamed intestinal tissue and postulated an in vivo pro-inflammatory role for the released TK (50). In previous studies, we also demonstrated an upregulation of gastric TK secretions in patients with gastritis $(34,51)$. Immunohistochemical examination of cervical cancer tissue also demonstrates extensive infiltration of inflammatory cells such as macrophages (29) and overexpression of the pro-inflammtory marker cyclooxygenase-2 (COX-2) (28). The pro-inflammatory functions of kinins may also account for the inflammation observed in cervical cancer. Kinin receptor antagonists may be a therapeutic approach as studies on celecoxib, a COX-2 inhibitor, have shown (27).

The discovery of the entire kallikrein genome has propagated numerous studies that implicate regulatory/dysregulatory TK expression and functional mechanisms in cancer and the associated processes of angiogenesis and metastasis. The concept of TK functional differences is also demonstrated in our tumour-angiogenesis model by the finding that HUVEC metabolites did not alter TK in either HeLa cells or its media. We have also ascertained in other experiments that neither HeLa nor neuroblastoma cells altered their TK secretion in response to the metabolites of each other (unpublished data). These results suggest that TK function and site of biological activity in cancer cells may be different from endothelial cells. However, there may be other factors (possibly endothelial or ECM-derived) that act in concert with tumour metabolites to enhance this response and mediate TK secretion exclusively in endothelial cells. Our model suggests that cancer cells are eliciting pro-angiogenic activity in HUVECs to proliferate, differentiate and migrate into the microenvironment under the influence of TK.

In conclusion, it is likely that tumour-induced, vascularderived TK that surrounds angiogenic endothelial cells: i) aids in stromal remodelling to allow angiogenesis and the release of contributing co-factors, ii) contributes to neo-vasculature invasiveness, and iii) produces a tempero-spatial chemotactic message that may be recognised by cell signalling systems. Various reports have hinted at the clinical value of tissue kallikreins as diagnostic and prognostic tools as well as future KKS agonist and/or antagonist drugs as feasible anti-cancer options. We intend to test this hypothesis by using inhibitors such as kallistatin or anti-TK antibodies in the challenge medium, and then determine changes in cell growth and invasion in the tumour angiogenic model.

\section{Acknowledgements}

The authors thank Mrs. Celia Snyman for her technical expertise in the image analysis work. The authors acknowledge the following South African institutions for funding part(s) of this project: Medical Research Council, National Research Foundation, Cancer Association of South Africa and the University of KwaZulu-Natal.

\section{References}

1. Garcia A: Cervical cancer. The Medscape Journal http:// www.emedicine.com/MED/topic324.html, 16 October, 2008.

2. Hockel S, Schlenger K, Vaupel P and Hockel M: Association between host tissue vascularity and the prognostically relevant tumor vascularity in human cervical cancer. Int J Oncol 19: 827-832, 2001

3. Phoophitphong T, Hanprasertpong J, Dechsukhum C and Geater A: Correlation of angiogenesis and recurrence-free survival of early stage cervical cancer patients undergoing radical hysterectomy with pelvic lymph node dissection. J Obstet Gynaecol Res 33: 840-848, 2007.

4. Wiggins DL, Granai CO, Steinhoff MM and Calabresi P: Tumor angiogenesis as a prognostic factor in cervical carcinoma. Gynecol Oncol 56: 353-356, 1995.

5. Cooper RA, West CM, Wilks DP, Logue JP, Davidson SE, Roberts SA and Hunter RD: Tumour vascularity is a significant prognostic factor for cervix carcinoma treated with radiotherapy: independence from tumour radiosensitivity. Br J Cancer 81: 354-358, 1999.

6. Vermeulen PB, Gasparini G, Fox SB, Toi M, Martin L, McCulloch P, Pezzella F, Viale G, Weidner N, Harris AL and Dirix LY: Quantification of angiogenesis in solid human tumours: an international consensus on the methodology and criteria of evaluation. Eur J Cancer 32A: 2474-2484, 1996.

7. Hlatky L, Hahnfeldt P and Folkman J: Clinical application of antiangiogenic therapy: microvessel density, what it does and doesn't tell us. J Natl Cancer Inst 94: 883-893, 2002.

8. Kisker O, Onizuka S, Becker C, Fannon M, Flynn E, D'Amato R, Zetter B, Folkman J, Ray R, Swamy N and Pirie-Shephard S: Vitamin D binding protein-macrophage activating factor (DBFmaf) inhibits angiogenesis and tumor growth. Neoplasia 5: 32-40, 2003.

9. Gargett CE, Bucak K and Rogers PAW: Isolation, characterization and long-term culture of human myometrial microvascular endothelial cells. Hum Reprod 15: 293-301, 2000.

10. Bischoff J: Cell adhesion and angiogenesis. J Clin Invest 99: 373-376, 1997.

11. Ferrer FA, Miller LJ, Andrawis RI, Kurtzman SH, Albertsen PC, Laudone VP and Kreutzer DL: Vascular endothelial growth factor (VEGF) expression in human prostate cancer: in situ and in vitro expression of VEGF by human prostate cancer cells. J Urol 157: 2329-2333, 1997.

12. Ferrara N: Vascular endothelium growth factor. Eur J Cancer 32A: 2413-2422, 1996.

13. Fidler IJ: Modulation of the organ microenvironment for treatment of cancer metastasis. J Natl Cancer Inst 87: 1588-1592, 1995.

14. Kodama J, Seki N, Tokumo K, Hongo A, Miyagi Y, Yoshinouchi M, Okuda H and Kudo T: Vascular endothelial growth factor is implicated in early invasion in cervical cancer. Eur J Cancer 35: 485-489, 1999.

15. Nishio S, Ushijima K, Tsuda N, Takemoto S, Kawano K, Yamaguchi T, Nishida N, Kakuma T, Tsuda H, Kasamatsu T, Sasajima Y, Kage M, Kuwano M and Kamura T: Cap43/ NDRG1/Drg-1 is a molecular target for angiogenesis and a prognostic indicator in cervical adenocarcinoma. Cancer Lett 264: 36-43, 2008.

16. Ueda M, Terai Y, Yamashita Y, Kumagai K, Ueki K, Yamaguchi H, Akise D, Hung YC and Ueki M: Correlation between vascular endothelial growth factor-C expression and invasion phenotype in cervical carcinomas. Int $\mathbf{J}$ Cancer 98: 335-343, 2002.

17. Pietras K, Pahler J, Bergers G and Hanahan D: Functions of paracrine PDGF signaling in the proangiogenic tumor stroma revealed by pharmacological targeting. PLoS Med 5: e19, 2008.

18. Emanueli C, Zacheo A, Minasi A, Chao J, Chao L, Salis M, Stacca T, Straino S, Capogrossi M and Madeddu P: Adenovirusmediated human tissue kallikrein gene delivery induces angiogenesis in normoperfused skeletal muscle. Arterioscler Thromb Vasc Biol 20: 2379-2385, 2000. 
19. Naidoo S, Raidoo D, Mahabeer R and McLean M: Tumour metabolites regulate tissue kallikrein in human umbilical vein endothelial cells. Biochim Biophys Acta 1691: 117-127, 2004

20. Yayama K, Kunimatsu N, Teranishi Y, Takano M and Okamoto H: Tissue kallikrein is synthesized and secreted by human vascular endothelial cells. Biochim Biophys Acta 1593: 231-238, 2003

21. Desrivieres S, Lu H, Peyri N, Soria C, Legrand Y and Menashi S: Activation of the $92 \mathrm{kDa}$ type IV collagenase by tissue kallikrein. J Cell Physiol 157: 587-593, 1993.

22. Saksela O: Plasminogen activation and regulation of pericellular proteolysis. Biochim Biophys Acta 823: 35-65, 1985

23. Koshikawa N, Yasumitsu H, Umeda M and Miyazaki K: Multiple secretion of matrix serine proteinases by human gastric carcinoma cell lines. Cancer Res 52: 5046-5053, 1992.

24. Dlamini Z, Raidoo DM and Bhoola KD: Tissue kallikrein and kinin receptors in oesophageal carcinoma. Immunopharmacology 43: 303-310, 1999

25. Hermann A, Buchinger P and Rehbock $\mathrm{J}$ : Visualisation of tissue kallikrein in human breast carcinoma by two-dimensional western blotting and immunohistochemistry. Biol Chem Hoppe Seyler 376: 365-370, 1995.

26. Farmer SG: The Kinin System. Academic Press Inc., San Diego, 1997.

27. Ferrandina G, Ranelletti FO, Legge F, Lauriola L, Salutari V Gessi M, Testa AC, Werner U, Navarra P, Tringali G, Battaglia A and Scambia G: Celecoxib modulates the expression of cyclooxygenase-2, ki67, apoptosis-related marker, and microvessel density in human cervical cancer: a pilot study. Clin Cancer Res 9: 4324-4331, 2003.

28. Young JL, Jazaeri AA, Darus CJ and Modesitt SC: Cyclooxygenase-2 in cervical neoplasia: a review. Gynecol Oncol 109: 140-145, 2008.

29. Mazibrada J, Ritta M, Mondini M, De Andrea M, Azzimonti B, Borgogna C, Ciotti M, Orlando A, Surico N, Chiusa L, Landolfo $\mathrm{S}$ and Gariglio $\mathrm{M}$ : Interaction between inflammation and angiogenesis during different stages of cervical carcinogenesis. Gynecol Oncol 108: 112-120, 2008.

30. Spiryda LB and Colman DR: Suppression of tumorigenicity in an aggressive cervical carcinoma induced by protein zero, a nervous system IgCAM. J Cell Sci 111: 3253-3260, 1998.

31. Kemme M, Podlich D, Raidoo D, Snyman C, Naidoo S and Bhoola K: Identification of immunoreactive tissue prokallikrein on the surface membrane of human neutrophils. J Biol Chem 380: 1321-1328, 1999

32. Bhoola KD, Elson CJ and Dieppe PA: Kinins - key mediators in inflammatory arthritis. Br J Rheumatol 31: 509-518, 1992.

33. Bhoola R, Ramsaroop R, Naidoo S, Muller-Esterl W and Bhoola KD: Kinin receptor status in normal and inflammed gastric mucosa. Immunopharmacol 36: 161-165, 1997.

34. Naidoo S, Ramsaroop R, Bhoola R and Bhoola K: The evaluation of tissue kallikrein in Helicobacter pylori-associated gastric ulcer disease. Immunopharmacology 36: 263-269, 1997.

35. Schacter M: Kallikreins (kininogenases) - A group of serine proteases with bioregulatory actions. Pharmacol Rev 31: 1-17, 1980.
36. Altman D: Practical Statistics for Medical Research. Chapman and Hall, London, 1991

37. Obiezu CV and Diamandis EP: Human tissue kallikrein gene family: applications in cancer. Cancer Lett 224: 1-22, 2005.

38. Clements JA: The molecular biology of kallikreins and their roles in inflammation. In: The Kinin System. Farmer SG (ed). Academic Press Inc., San Diego, CA, pp71-98, 1997.

39. Matsumura Y, Maruo K, Kimura M, Yamamoto T, Konno T and Maeda $\mathrm{H}$ : Kinin-generating cascade in an advanced cancer patient: an in vitro study. Jpn J Cancer Res 82: 732-741, 1991.

40. Raidoo D, Sawant S, Mahabeer R and Bhoola KD: Kinin receptors are expressed in human astrocytic tumour cells. Immunopharmacology 43: 255-263, 1999.

41. Rehbock J, Buchinger P, Hermann A and Figueroa C: Identification of immunoreactive tissue kallikrein in human ductal breast carcinomas. J Cancer Res Clin Oncol 121: 64-68, 1995.

42. Shaw JL and Diamandis EP: A potential role for tissue kallikreinrelated peptidases in human cervico-vaginal physiology. Biol Chem 389: 681-688, 2008.

43. Rixon RH and Whitfield JF: Kininogenases, kallikrein. Schattauer-Verlag, Stuttgart, 1973.

44. Bhoola KD, Figueroa CD and Worthy K: Bioregulation of kinins: Kallikreins, kininogens and kininases. Pharmacol Rev 44: 1-80, 1992.

45. Chao J, Stallone JN, Liang Y-M, Chen L-M, Wang D-Z and Chao L: Kallistatin is a potent new vasodilator. J Clin Invest 100: $11-17,2000$

46. Chao J, Tillman DM, Wang MY, Margolius HS and Chao L: Identification of a new tissue - kallikrein-binding protein. Biochem J 239: 325-331, 1986.

47. Shih Ie M, Salani R, Fiegl M, Wang TL, Soosaipillai A, Marth C, Muller-Holzner E, Gastl G, Zhang Z and Diamandis EP: Ovarian cancer specific kallikrein profile in effusions. Gynecol Oncol 105: 501-507, 2007

48. Guo P, Xu L, Pan S, Brekken R, Yang S-T, Whitaker G, Nagane M, Thorpe P, Rosenbaum J, Huang H-J, Cavanee WK and Cheng S-Y: Vascular endothelial growth factor isoforms display distinct activities in promoting tumor angiogenesis at different anatomic sites. Cancer Res 61: 8569-8577, 2001.

49. Stadnicki A, Chao J, Stadnicki I, van Tol E, Lin K-F, Li F, Sartor B and Colman RW: Localization and secretion of tissue kallikrein in peptidoglycan-induced enterocolitis in Lewis rats. Am J Physiol 275: G854-G861, 1998.

50. Stadnicki A, Mazurek U, Gonciarz M, Plewka D, Nowaczyk G, Orchel J, Pastucha E, Plewka A, Wilczok T and Colman RW: Immunolocalization and expression of kallistatin and tissue kallikrein in human inflammatory bowel disease. Dig Dis Sci 48: 615-623, 2003

51. Naidoo S: The role of tissue kallikrein in Helicobacter pyloriassociated gastric disease. Clinical and Experimental Pharmacology, University of Natal Medical School, University of Natal Library, Durban, p203, 1999. 